Rev. Adm. Saúde (On-line), São Paulo, v. 19, n. 74, jan. - mar. 2019, Epub 18 mar. 2019 http://dx.doi.org/10.23973/ras.74.159

ARTIGO ORIGINAL

\title{
Gestão do agendamento de exames periódicos em um hospital público do estado de São Paulo
}

Management of the periodic exams scheduling of a public hospital in the State of São Paulo

\section{Eulália Oliveira Bekkers ${ }^{1}$, Raphael Kaeriyama e Silva², Ana Cláudia Becker $^{3}$, Nancy Val y Val Peres da Mota ${ }^{4}$}

1. Cirurgiã-dentista especialista em administração hospitalar e de sistemas de saúde. Aprimoranda do Programa de Estudos Avançados em Administração Hospitalar e Sistemas de Saúde (PROAHSA) do Hospital das Clínicas da Faculdade de Medicina da USP (HCFMUSP), São Paulo SP.

2. Médico especialista em administração hospitalar e de sistemas de saúde. Médico residente do PROAHSA do HCFMUSP, São Paulo SP.

3. Gerontóloga especialista em administração hospitalar e de sistemas de saúde. Aprimoranda do PROAHSA do HCFMUSP, São Paulo SP.

4. Médica especialista em administração hospitalar e sistemas de saúde. Membro do corpo técnico do PROAHSA do HCFMUSP, São Paulo SP.

\section{RESUMO}

Objetivo: Analisar as principais falhas na gestão do agendamento dos exames periódicos de um hospital público de alta complexidade do Estado de São Paulo. Metodologia: Estudo descritivo, com utilização de levantamento bibliográfico, visitas observacionais no local, análise de dados disponibilizados pelo setor e entrevistas com os atores-chaves envolvidos no sistema de agendamento; afim de descrever o cenário, analisar as principais falhas e propor melhorias. Resultados: Foi possível constatar que o modelo de agendamento de exames periódicos que vem sendo utilizado é composto por um número excessivo de profissionais e de processos envolvidos, sendo a maioria destes realizados manualmente; chegando a um resultado final que 
não é eficiente, uma vez que, até abril deste ano, $48 \%$ dos funcionários da instituição apresentavam seus exames periódicos vencidos, a oferta de serviços não supria a demanda e a média de absenteísmo para aqueles que conseguiram marcar os exames foi de $20 \%$. Conclusão: Uma melhor gestão do agendamento permite uma maior agilidade na realização dos exames e consequentemente um aumento da satisfação dos clientes.

Palavras-chave: agendamento de exames; exame médico periódico; saúde do trabalhador; medicina do trabalho.

\section{ABSTRACT}

Objective: Analyze the main failures in the management of the periodic exams scheduling of a high complexity public hospital in the State of São Paulo.

Methodology: Descriptive study, using a bibliographical survey, observational site visits, analysis of data made available by the sector and interviews with the key actors involved in the scheduling system; in order to describe the scenario, analyze the main failures and propose improvements. Results: It was confirmed that the model of scheduling of periodic exams, is composed by an excessive number of professionals and processes involved, and the majority of these are manuals; reaching an end result that is not efficient, since up to April of this year, $48 \%$ of the institution's employees had their periodic exams expired, the service offer did not meet the demand and the average absenteeism was $20 \%$ for those who succeed to schedule their periodic exams. Conclusion: A better management of the periodic exams scheduling improves agility in performing the exams and consequently increase the customer satisfaction.

Keywords: exams scheduling; periodic medical examination; occupational medicine; occupational health.

\section{INTRODUÇÃO}

Ligado ao setor de gestão de pessoas de um complexo hospitalar público do estado de São Paulo, o Serviço de Atenção ao Colaborador (SAC), que existe desde a década de 50, é responsável pela gestão da saúde e segurança dos colaboradores do complexo. Em 2017, passou por uma reestruturação e mudança de local, a fim de expandir, inovar e trazer mais qualidade ao serviço. O SAC conta com um pronto atendimento, para atender emergências, um ambulatório e o Serviço Especializado em Engenharia de Segurança e em Medicina do Trabalho (SESMT). 
No Brasil, a regulamentação da medicina do trabalho teve início em 1978, por meio da Portaria $n^{\circ} 3.214$ de 1978, que aprova as Normas Regulamentadoras (NRs) do Ministério do Trabalho e Emprego $(1,2)$. Para um melhor entendimento do tema, três destas Normas estão resumidas a seguir:

A Norma Regulamentadora 4 (NR-4), prevê em seu item 4.1 que as empresas devem, obrigatoriamente, manter os SESMT com a finalidade de promover a saúde e proteger a integridade do trabalhador no local de trabalho, sendo que o dimensionamento do serviço vincula-se a gradação de risco da atividade principal da empresa e ao número total de empregados do estabelecimento (3).

A NR-7 estabelece que as empresas devem ser responsáveis pelo Programa de Controle Médico de Saúde Ocupacional (PCMSO) de seus colaboradores, com caráter de prevenção, rastreamento e diagnóstico dos agravos à saúde relacionados ao trabalho, inclusive de natureza subclínica, além da constatação da existência de casos de doenças profissionais ou danos à saúde dos trabalhadores, com a obrigatoriedade dos exames admissional, periódico, de retorno ao trabalho, mudança de função e demissional (4).

Já a NR-9 obriga a elaboração e implementação do Programa de Prevenção de Riscos Ambientais (PPRA), visando à preservação da saúde e da integridade dos trabalhadores, através da antecipação, reconhecimento, avaliação e consequente controle da ocorrência de riscos ambientais existentes ou que venham a existir no ambiente de trabalho (5).

Contudo, a existência de leis não tem sido suficiente para transformar a realidade da saúde do trabalhador, em especial, no contexto do SUS (6). Conforme a complexidade da empresa, área de abrangência, número de estabelecimentos, o grau de risco das atividades laborais e o número de empregados, a gestão do PCMSO pode representar um grande desafio (7).

O SESMT, um dos principais serviços do Centro de Atenção ao Colaborador, opera em sua capacidade total para o bem-estar laboral de aproximadamente 23.000 funcionários que atuam nos 11 Institutos que compõem a instituição. Por ter uma grande demanda e atrasos em alguns de seus processos, como o agendamento e a realização de exames periódicos, estes precisam ser revistos. O interesse em propor este estudo nasceu também a partir de observações no setor e de uma demanda da área.

O projeto tem como objetivo principal analisar as principais falhas na gestão do agendamento dos exames periódicos de um hospital público de alta complexidade do Estado de São Paulo. Tendo como objetivos específicos descrever o sistema de agendamento atual, identificar suas principais falhas e propor melhorias, a fim de adequar a oferta a demanda e proporcionar aos colaboradores uma experiência positiva.

\section{METODOLOGIA}


Trata-se de uma pesquisa descritiva, realizada de abril a junho de 2018, no Serviço de Atenção ao Colaborador de um hospital público de alta complexidade do Estado de São Paulo. O estudo buscou contemplar: um levantamento bibliográfico sobre o tema, visitas observacionais no local (acompanhando desde a chegada do paciente até a finalização do atendimento), uma análise dos dados disponibilizados pelo setor de agendamento de exames e entrevistas com os atores-chaves envolvidos no sistema de agendamento; permitindo assim, descrever o cenário atual e analisar as principais falhas na gestão do agendamento de exames periódicos.

Para realização da análise dos dados de agendamento, foram colhidas informações das planilhas de controle de marcação de exames, preenchidas no Excel por diferentes atores. A base de dados analisada continha informações de data e tipos de exames agendados durante o período de janeiro a abril de 2018. Para estudo da demanda de exames periódicos, foram analisados 0 número total de pacientes que necessitam realizar esse tipo de exame (funcionários ativos), o número de consultas agendadas por mês e o percentual de falta às consultas agendadas. Como critério de seleção dos entrevistados, utilizou-se pelo menos um ator-chave para cada macroprocesso do agendamento, totalizando sete sujeitos.

Por fim, com base na literatura e em benchmarkings realizados em 2 instituições de referência na área, foram propostas algumas melhorias para a gestão de agendamento no SAC.

\section{RESULTADOS E DISCUSSÃO}

\section{Descrição do sistema de agendamento atual}

O SAC possui 10 médicos do trabalho responsáveis pelos exames periódicos, com tempos de jornadas diferentes. Estes realizam exames periódicos para um total de 14.381 funcionários ativos, num serviço que funciona apenas de segunda a sexta-feira. Quando os colaboradores apresentam risco ocupacional, que no caso da instituição em estudo representa a grande maioria dos funcionários, a rotina de realização de exames periódicos deve ser repetida anualmente. Atualmente, são disponibilizadas 800 vagas mensais para realização deste tipo de exame, considerando-se 22 dias úteis por mês, tem-se em média 36 vagas disponibilizadas por dia. Analisando a relação oferta versus demanda, a quantidade de periódicos agendados anualmente não contempla a demanda.

Quanto ao modelo de agendamento atual, a partir de observações realizadas no local, das planilhas de agendamento disponibilizadas pelo setor (com exames agendados e/ou realizados de janeiro a abril de 2018) e de entrevistas com os atores-chaves envolvidos em todas as etapas do agendamento de exames médicos periódicos na instituição, foi possível constatar que o modelo de gestão do agendamento que vem sendo utilizado é composto por cinco diferentes atores e envolve seis macroprocessos, como mostra a Figura 1. 
Considerando que cada ator é composto por mais de um profissional responsável, podemos concluir que há um número excessivo de profissionais envolvidos diretamente no agendamento dos exames periódicos. Mesmo com um gasto grande de energia e o despendimento de recursos humanos especializados, o resultado final não é eficiente, uma vez que, até abril deste ano, $48 \%$ dos funcionários da instituição apresentavam seus exames periódicos vencidos. Quanto aos colaboradores que haviam consulta marcada no período avaliado, a média de absenteísmo foi de $20 \%$, podendo variar até $31 \%$ a depender do Instituto. É importante ressaltar que, estes dados são coletados através de planilhas Excel alimentadas manualmente e que nem sempre são fidedignos.

Há diversos motivos que podem ser apontados como influentes nessa operação falha, tais quais: pouca confiabilidade no serviço, cultura deficiente da instituição em relação à promoção a saúde e qualidade de vida, existência de muitas etapas e processos no agendamento que não agregam valor, falhas de comunicação entre os diversos setores envolvidos, número reduzido de profissionais (sendo que muitos deles trabalhando apenas 20 horas semanais), má distribuição das agendas, falta de padronização no sistema de agendamento entre os 11 Institutos, dentre outros.

A seguir, um esquema ilustrativo do atual sistema de agendamento de exames periódicos da instituição, acompanhado pela descrição dos atores envolvidos neste sistema de agendamento e o do detalhamento de cada macroprocesso e subprocesso:

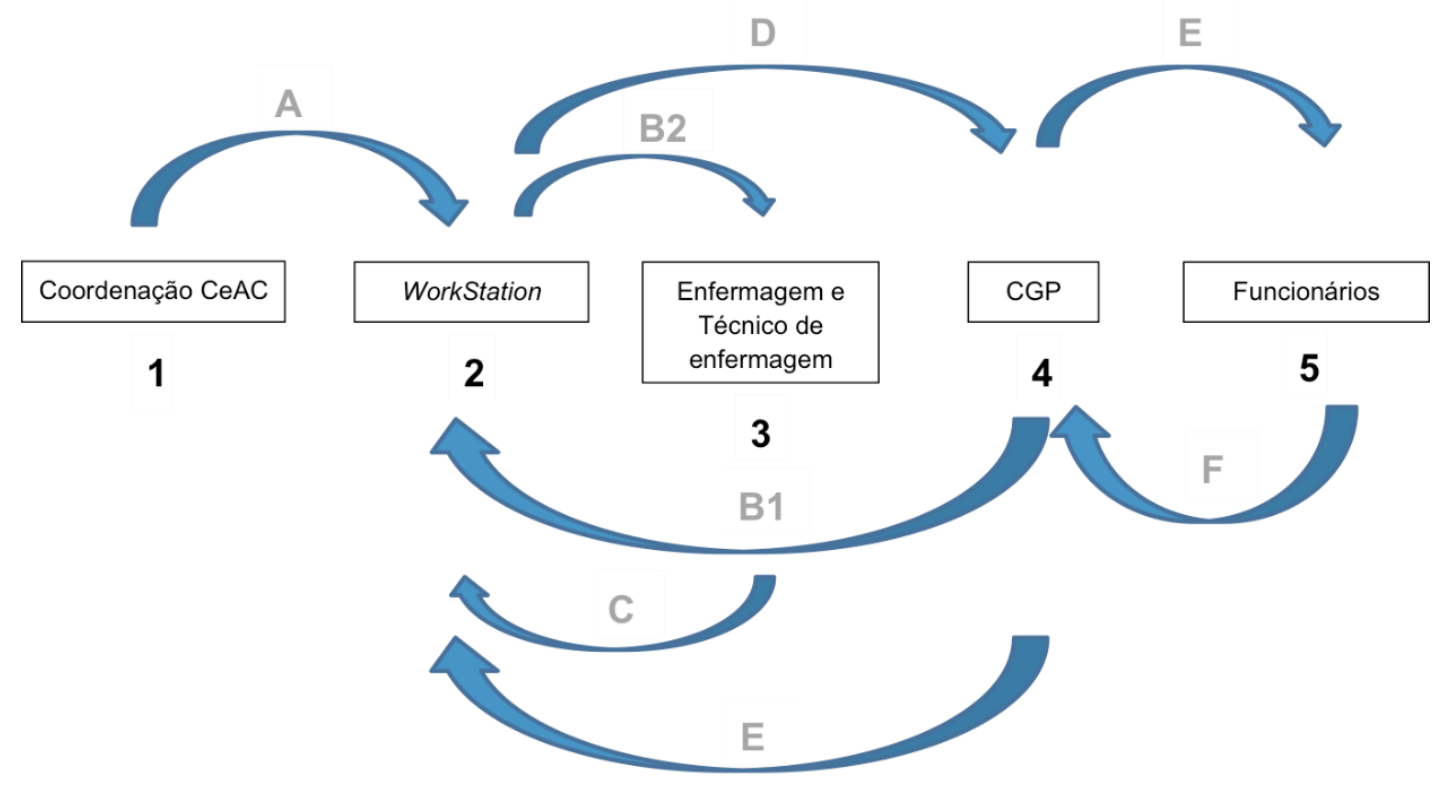

Figura 1. Esquema ilustrativo do modelo de gestão do agendamento de exames periódicos utilizado pelo SAC 
Atores do sistema de agendamento:

1) Coordenação SAC (Diretor médico e coordenadora médica);

2) WorkStation (WS);

3) Enfermeira e técnica de enfermagem;

4) Centro de Gestão de Pessoas (CGP) - são 11, sendo um por instituto;

5) Funcionários (que neste caso são os pacientes).

Macroprocessos:

A) Configuração da agenda (divisão da proporção dos diferentes tipos de exames ocupacionais na agenda de cada médico);

B) Gestão das vagas para cada Instituto que compõe o Complexo;

C) Seleção dos exames seguindo os grupos de risco do PPRA;

D) Envio das vagas disponíveis para agendamento e dos exames necessários para cada funcionário;

E) Divulgação dos agendamentos em forma de planilha Google Docs para o WorkStation e para os funcionários.

F) Escolha do melhor período e/ou confirmação do agendamento*

* O agendamento das vagas disponibilizadas no Google Docs pode ser feito tanto pelo CGPs quanto pelos próprios funcionários, a depender do Instituto. 
Subprocessos de B e C:

B1) O WorkStation recebe dos CGPs a quantidade necessária de exames periódicos para cada Instituto.

B2) O WorkStation soma a quantidade de vagas disponibilizadas para cada período, de acordo com a configuração da agenda estabelecida pela Coordenadoria do SAC, e separa as vagas para cada Instituto, tentando levar em consideração a demanda de cada um deles. O absenteísmo do período anterior é avaliado e os Institutos com menores taxas têm mais vagas disponíveis para agendamento.

C1) Enfermagem faz a correlação dos exames necessários seguindo o PPRA para cada funcionário, de forma manual.

C2) Técnico de enfermagem carimba cada uma das solicitações, com carimbos específicos para cada grupo de risco do PPRA e com o carimbo de solicitação do médico responsável.

\section{Principais falhas do sistema de agendamento atual}

A forma como o agendamento é realizado atualmente acaba gerando uma série de problemas no processo como um todo. Para cada etapa do processo há diversos gargalos, estes serão detalhados a seguir.

A) Configuração da agenda:

- Existe uma variação mensal na configuração da agenda, tanto da quantidade quanto nos tipos de exames para cada um dos médicos, o que acaba gerando retrabalho e complexidade aos outros processos da cadeia.

- Parte do trabalho operacional está sendo realizado pela coordenação e diretoria do serviço, sendo que estes profissionais poderiam estar aproveitando este tempo para realizar funções mais estratégicas.

- A configuração da agenda está sendo feita com base no perfil do profissional médico. Por exemplo, se um médico tem mais facilidade em realizar exames admissionais, a agenda será configurada para que este tipo de exame seja realizado preferencialmente por este profissional, o que muitas vezes gera uma má distribuição da oferta versus demanda. Além de condicionar o profissional a só realizar aquele tipo de exame.

- Os tempos destinados às consultas ocupacionais são longos (40 minutos).

B) Gestão das vagas: 
- As bases de dados dos funcionários ativos não são atualizadas pelos responsáveis, que seriam os Centros de Gestão de Pessoas, dificultando definir quais são os funcionários ativos e quais são os afastados.

- A gestão das vagas envolve vários processos manuais (onde os dados são inseridos em planilhas no Excel) e repetitivos (variam todo mês devido as variações na configuração das agendas).

- Demora para realização de todos os subprocessos.

C) Seleção dos exames seguindo o PPRA:

- A enfermagem realiza a separação manual dos exames necessários para cada funcionário (um por um), podendo variar mensalmente.

- Demora para a realização dos processos.

D) Envio das vagas disponíveis para agendamento:

- Duplicação de tarefas (envio das solicitações de exames específicos de cada funcionário por via física e digital).

- "Terceirização" da responsabilidade para os CGPs de entregarem as solicitações de exames para cada funcionário.

E) Divulgação dos agendamentos:

- Os CGPs divulgam tardiamente as datas do agendamento, deixando pouco tempo para o funcionário conseguir realizar os exames de laboratório e se preparar para a consulta periódica.

- Estratégia de pressão e obrigação dos CGPs para a realização dos periódicos, quando estes deveriam ser apresentados como um benefício.

- Falta de uniformidade no preenchimento das vagas disponíveis (varia para cada Instituto, sendo possível o CGP ou os próprios funcionários preencherem o Google Docs disponibilizado).

- Falta de sigilo (todos tem acesso à dados como exames necessários, pendências de vacinação, etc.).

- Divulgação deficiente para os funcionários (pelos CGPs). 
F) Escolha do melhor período e/ou confirmação do agendamento:

- Falta de incentivo e confiabilidade no serviço médico, fazendo com que os funcionários não preencham as vagas disponíveis para o exame médico periódico.

\section{Benchmarking}

Através de benchmarkings realizados em duas instituições de referência na área de saúde ocupacional, foi possível realizar algumas comparações entre a gestão do agendamento de exames periódicos realizados no SAC e nestas duas instituições (um hospital filantrópico do município de São Paulo e uma multinacional que possui uma rede de indústrias distribuídas pelo Brasil).

\section{Hospital filantrópico}

O hospital filantrópico possui cerca de 3.300 funcionários e um serviço de medicina ocupacional (SMO) que conta com 4 médicos para atender sua população (sempre ficam 2 médicos no setor, 1 atendendo os exames ocupacionais e o outro os assistenciais). O serviço tem comunicação direta com os funcionários, não precisando passar por chefias ou recursos humanos, visando assim uma maior confidencialidade dos funcionários. $O$ agendamento de exames periódicos é feito de acordo com a data do último atendimento de saúde ocupacional realizado, através de um sistema automatizado.

Neste hospital, o exame periódico é chamado de consulta bem-estar periódica, já voltada para o programa de qualidade de vida. As agendas têm um tempo de 30 minutos por consulta, o serviço conta com, no mínimo, um médico clínico para questões ocupacionais e outro para questões assistenciais (pronto atendimento, retorno de atestado, entre outros). O cálculo da demanda é feito no primeiro dia útil do ano, considerando o total de funcionários dividido pela quantidade de dias úteis naquele ano, dividido por área, o que dá uma média de 13 exames periódicos por dia. Considerando-se 22 dias úteis por mês, daria 3.432 exames, o que já cobre a demanda deste hospital.

Um dia antes do exame, o funcionário é notificado através da intranet, na catraca, no relógio de ponto, e as secretarias do SMO ainda ligam para confirmar. Com a adoção dessa sistemática, a taxa média de adesão para os exames periódicos passou de $47 \%$ para $97 \%$ desde que o modelo atual foi adotado, há 4 anos. Previamente a consulta, o colaborador preenche um questionário de saúde e estilo de vida, este questionário gera um "saudômetro" que ajuda a orientar a consulta.

No hospital foi implantado também um programa de bem-estar para o colaborador, onde suas metas de saúde estão relacionadas à sua remuneração variável. Esse programa fez com que a adesão dos funcionários aos exames ocupacionais aumentasse. O questionário sobre saúde e estilo de vida também 
faz parte do programa e seu preenchimento conta pontos que ajudam a alcançar metas de saúde e bem-estar. A remuneração pode ser até 1,5 vezes o salário e existem pontos a serem "conquistados", equivalentes a $10 \%$ desse bônus. Funcionários com mais de 15 ocorrências (atestados ou faltas) no ano, têm um decréscimo de 10 a $15 \%$ do bônus.

Os pedidos de exames periódicos são enviados direto para o laboratório cerca de um mês antes do exame e, o funcionário sabendo previamente a data, já se encaminha diretamente ao local de coleta, a enfermagem deixa o pedido de cada um pronto para mandar ao laboratório. Os setores são divididos por mês para a realização do periódico para não haver desfalque de pessoal. O gestor acompanha apenas se as metas de periódicos de sua equipe estão em dia. Para quem tem um algum desajuste nos exames, há uma convocação do SMO.

\section{Multinacional}

O primeiro ponto mencionado pelo gerente médico responsável pelo serviço de medicina ocupacional da sede da empresa foi sobre a necessidade de implementar a cultura da instituição desde o processo admissional dos funcionários. Esta empresa estimula uma rotina saudável logo no processo de integração, no qual são passados todos os benefícios oferecidos, além de mostrar o programa Vibrant Living. Este programa é responsável pela qualidade de vida e de trabalho dos funcionários, uma vez que estimula sua promoção à saúde, tendo como intenção final transformá-lo em um multiplicador da cultura saudável. Para isso, foi construída uma marca forte, na qual os funcionários podem identificar tudo que o programa apoia, como, alimentos saudáveis, prática de atividade física, massagem, etc. A empresa acredita que demonstrando a cultura logo no processo admissional, aproxima os funcionários da medicina do trabalho, o que gera maior engajamento e confiabilidade no serviço de saúde ocupacional e, consequentemente, redução dos custos de saúde.

Outro ponto abordado foi em relação à estratégia de agendamento. No dia do aniversário do colaborador é enviado um e-mail lembrando do exame periódico, o qual é agendado com a enfermeira do próprio ambulatório que se encontra na empresa. Cada unidade desta multinacional apresenta um núcleo próprio de medicina do trabalho, dimensionada especificamente com a demanda característica de cada serviço, e cada núcleo realiza seu próprio agendamento. No lembrete do exame periódico também é estimulado o preenchimento do questionário wellness check point, uma ferramenta de gestão da saúde que armazena informações diversas do funcionário, tais como: comorbidades, estilo de vida, riscos de saúde, saúde psicológica, ambiente familiar, etc. Através dele, o médico do trabalho pode estabelecer planos de ação organizacionais uma vez que tem acesso a dados epidemiológicos e as necessidades de maiores prevalências. Além disso, o questionário mostra uma página confidencial a cada funcionário com seu resultado individual, a qual evidencia os pontos de melhoria para atingir as metas esperadas de cada um. 
Por fim, foi pontuada a importância dos indicadores e metas, e que para se ter um serviço de medicina do trabalho eficiente, é fundamental que haja confiabilidade dos funcionários com o serviço prestado.

Comparação do SAC com as instituições visitadas

Enquanto no SAC a configuração das agendas dos médicos varia mensalmente (figura 1), nas duas empresas visitadas há uma tentativa de estabilidade e manutenção da data do periódico de cada funcionário. No hospital filantrópico cada funcionário tem uma data e horário específico no ano, que se mantem constante (exceção para casos de impossibilidade e consequente reagendamento). Já na multinacional, a estratégia utilizada é baseada na data de aniversário do funcionário, período em que a enfermeira do centro médico envia um e-mail para o funcionário solicitando que agende seu exame periódico.

Em ambos os serviços analisados pelo benchmarking é possível estabelecer algumas características em comum do agendamento que diferem do SAC (figura 2):

- A responsabilidade do agendamento é do centro médico e do funcionário, sem intervenção do setor de recursos humanos;

- Existe uma comunicação direta do funcionário com o laboratório para solicitação dos exames específicos;

- Estratégia para agendamento dos exames periódicos visando manter datas recorrentes. 


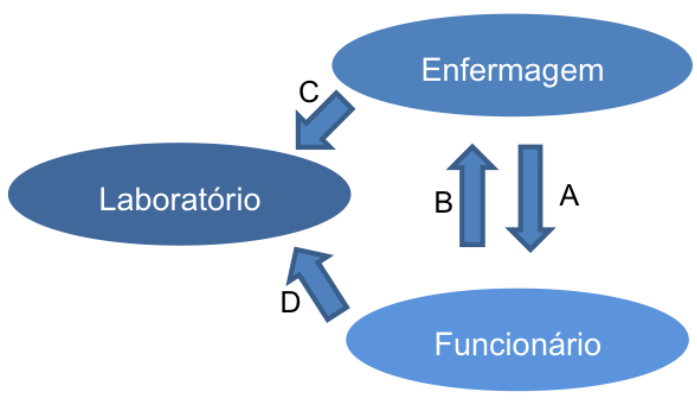

Agendamento sempre na mesma data
Sede da multinacional (800 funcionários)

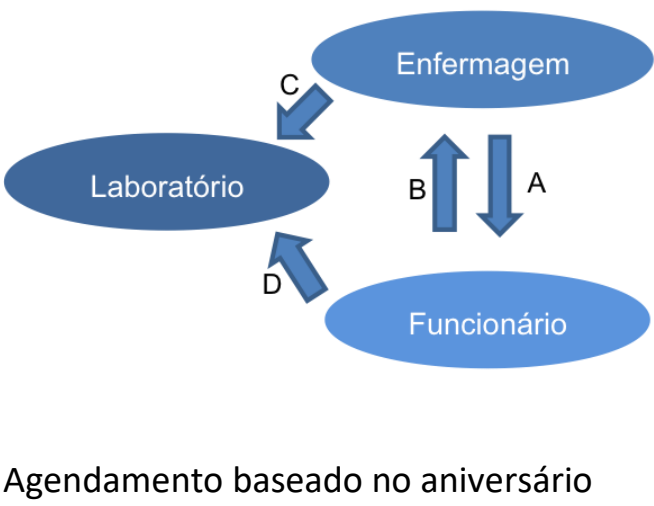

Figura 2. Ilustração do sistema de agendamento de exames periódicos nas 2 instituições visitadas.

\section{Propostas de melhorias}

Segundo Braun et al. (2016, p.77), os serviços de medicina do trabalho precisam se organizar para oferecer atendimento com qualidade, além de ofertar serviços inovadores e diferenciados para atender a demanda constante da sociedade pelo seu bem-estar (8). Considerando o mundo dinâmico em que se vive, onde as pessoas têm cada vez menos tempo, a realização de melhorias e modificações nos processos de uma organização se torna fundamental para fidelização do cliente, agilidade dos processos e eficiência no atendimento. Igualmente, a participação do trabalhador na gestão dos exames médicos do PCMSO é fundamental no controle de qualidade do serviço prestado e na busca de melhoria contínua (7). O presente projeto propõe um novo modelo de gestão do agendamento de exames para o SAC, baseado em três pilares (Figura 3): 


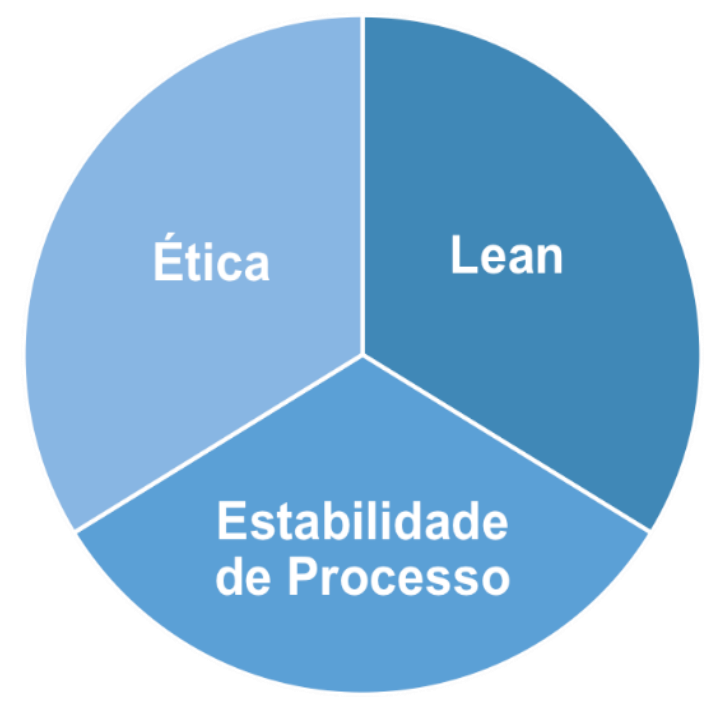

Figura 3. Pilares do modelo de gestão do agendamento proposto.

\section{Lean (enxuto)}

"A utilização da mentalidade Lean no gerenciamento de projetos se justifica pelos ganhos que podem ser obtidos na eliminação de algumas etapas desnecessárias que geram desperdícios, identificando corretamente o fluxo de valor do projeto, e auxiliando na diminuição do grau de incertezas". Em suma, a mentalidade Lean é fazer mais com menos, e ao mesmo tempo dar aos clientes o que eles querem (9).

O modelo propõe que apenas quatro atores sejam responsáveis pelo processo de agendamento, sendo estes: o WorkStation, os funcionários (pacientes), os Centros de Gestão de Pessoas (CGPs) e o Laboratório Central - DLC (Figura 4). O macroprocesso "A", destinado à configuração de agenda não deve ser realizado mensalmente, e sim previamente configurado com pelo menos seis meses de antecedência. Desta forma, os agendamentos podem ser feitos com tempo hábil para que os funcionários realizem os exames laboratoriais necessários para o seu exame periódico. Além disso, a configuração da agenda deve ser de responsabilidade do WorkStation. As coordenadorias médica e administrativa devem acompanhar todo o processo apenas através de indicadores de desempenho, pois a responsabilidade operativa da agenda não deve ser da alta gestão. 


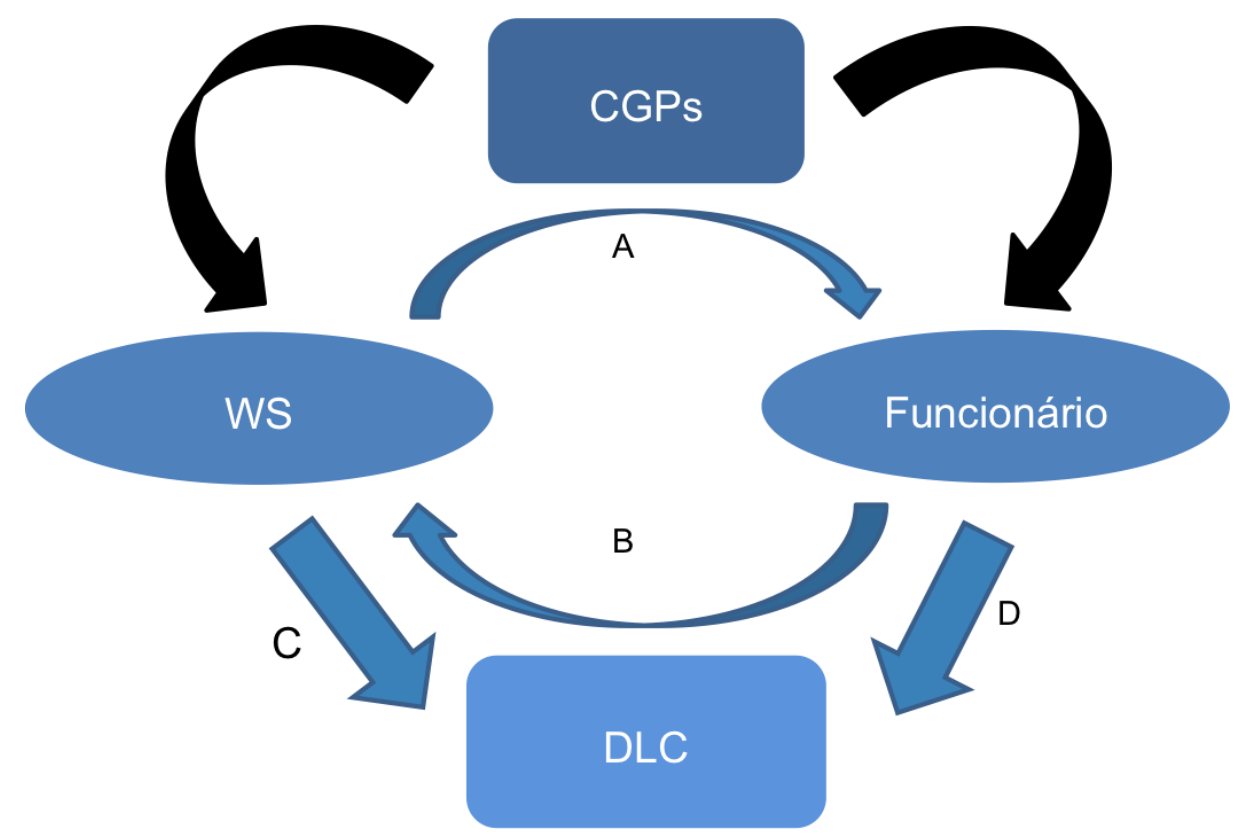

Figura 4: Esquema ilustrativo do modelo de gestão do agendamento proposto.

Outros atores a serem retirados do processo de gestão do agendamento são os enfermeiros e técnicos de enfermagem. Atualmente eles são responsáveis por definir os exames necessários para todos os funcionários indicados pelos CGPs, segundo o risco que possuem, e carimbam cada pedido com a classificação realizada. Essa ação é feita todo mês e, como há variabilidade de agenda, esse processo acaba sendo muito longo e requer um gasto de energia muito alto. Além disso, como a demanda supera a oferta, nem todos os funcionários indicados pelos CGPs são atendidos. Assim, todo mês há um grande número de funcionários que são classificados de acordo com seus riscos e que, por falta de oferta na agenda, não serão nem agendados para realizar o periódico. Propõe-se então que haja um critério base de agendamento seguindo os riscos dos pacientes, de forma que todos os funcionários que farão exames periódicos em um determinado período tenham os mesmos riscos e, consequentemente, a mesma classificação e o mesmo carimbo na solicitação de exames. Dessa forma, não precisaríamos classificar todos os funcionários todos os meses do ano.

A cada mês, as solicitações de exames teriam o mesmo carimbo e seriam enviadas diretamente ao Laboratório Central, que já saberia de antemão quais os funcionários que viriam realizar o mesmo pacote de exames dentro do período determinado.

Outra sugestão é que a lista dos funcionários separados pelos grupos de controle ocupacional específicos e pelas categorias abrangentes seja solicitada aos CGPs. Assim, tendo a quantidade de funcionários para cada código, a WS poderia calcular os períodos necessários para cada grupo. Além disso, no momento da divisão dos períodos os grupos deverão ser priorizados segundo os graus de risco (quanto maior o risco, maior o tempo disponibilizado). 
Ética

Segundo Villas-Bôas (2015, p.514), "o sigilo ou segredo profissional foi contemporaneamente associado ao princípio bioético da autonomia, vez que, pertencendo os dados pessoais ao paciente, apenas ele pode decidir, a priori, a quem deseja informá-los" (10).

O sigilo médico é algo que deve ser sempre valorizado, principalmente em uma Instituição de saúde de grande porte e relevância. Dessa forma, propõe-se uma menor intervenção dos Centros de Gestão de Pessoas, uma vez que, da forma como ocorre a gestão atual do agendamento, informações sobre os exames a serem realizados e sobre o status atual de acompanhamento do periódico podem ser visualizados por pessoas que não estejam autorizadas pelo paciente. O modelo propõe que o agendamento seja baseado em uma relação direta entre o WorkStation e os funcionários de forma que possam escolher 0 melhor horário possível para cada um. Assim, espera-se uma redução do absenteísmo presencial. Para evitar o absenteísmo de agenda, sugere-se que os Centros de Gestão de Pessoas tenham apenas um papel de regulador do processo. Os CGPs teriam acesso aos agendamentos, porém apenas às informações referentes à agenda, e não aos exames solicitados. Em caso de funcionários do mesmo setor estarem agendados no mesmo período, seria de responsabilidade do CGP entrar em contato com os funcionários e solicitar para alterarem a agenda. Com esta proposta, o sigilo médico e consequentemente a confiabilidade no serviço seria maior.

\section{Estabilidade de processo}

O modelo proposto foca na importância da estabilidade do processo. A variabilidade do agendamento atual leva a inúmeros gargalos e erros de agenda, que somados à crença de carência de resolutividade e baixa confiança no serviço de medicina do trabalho da instituição, não favorecem a realização dos exames periódicos. Assim, sugere-se que os agendamentos sigam um mesmo padrão todos os anos e que os mesmos grupos de riscos realizem os exames sempre nos mesmos períodos. Os funcionários devem estar cientes de que todos os anos, preferencialmente naquele mesmo período, deverão realizar seus exames periódicos. Portanto, o modelo proposto pretende estabilizar a configuração da agenda, o critério de agendamento baseado nos riscos e os períodos selecionados para cada grupo de risco.

Em caso de necessidade de encaixe por não comparecimento ao exame periódico, propõe-se que haja um monitoramento pelo CGP dos absenteístas (através de relatórios de comparecimento realizados periodicamente pelo WS) e solicitação direta para que o WS agende esses casos. Assim, o CGP atua como regulador do processo geral, e como interventor nos casos de absenteísmo. 
Para que o serviço reduza as taxas de absenteísmo é necessário que o WS envie lembretes aos funcionários, lembrando dos exames médicos periódicos, uns dois dias antes da consulta. Ter um software que envie lembretes via email ou SMS facilitaria esta gestão. Um sistema de agendamento eletrônico também é uma ferramenta importante para agilizar a revisão e melhoria dos processos de gestão (11).

\section{Plano de ação}

Para implementar o modelo proposto sugere-se a realização de um projeto piloto com algum dos grupos de risco utilizados pelo SAC (Quadro 1). Assim, após escolher um dos grupos (preferencialmente de alto risco), e calculada a demanda, seria definido um período em que todos os exames agendados seriam de funcionários do mesmo grupo de risco, e consequentemente com as mesmas necessidades de exames. Esses exames seriam enviados diretamente ao Laboratório Central da instituição e os funcionários se dirigiriam até lá para a realização dos mesmos, sem precisar da intervenção dos Centros de Gestão de Pessoas.

Quadro 1. Classificação dos grupos de risco utilizados pelo SAC

\begin{tabular}{|l|l|}
\hline 0 - SRO - Sem Risco Ocupacional & SRO \\
\hline A - Biológico - Agentes Biológicos & \\
\hline A - Biológico - Agentes Biológicos & BIO - A \\
\hline A - Biológico - Agentes Biológicos & BIO - A1 \\
\hline C - Biológico - Manutenção de águas & BIO - C \\
\hline D - Biológico - Pesquisa & BIO-D \\
\hline D - Químico - Produtos Químicos em Geral & QUI-D \\
\hline E - Químicos - Quimioterápicos & QUI-E \\
\hline F - Químico - Tolueno & QUI-F \\
\hline G - Químico Xileno & QUI-G \\
\hline H - Químico - Agentes Químicos & QUI-H \\
\hline J - Físico - Radiação lonizante & FIS-J \\
\hline L - Físico Ruído & FIS-L \\
\hline
\end{tabular}




\begin{tabular}{|l|l|}
\hline M - Químico - Hormônios Sexuais Femininos & \\
\hline Manipulação de Alimentos & CVS \\
\hline Distribuição de Alimentos & CVS-DA \\
\hline Controle para Motoristas de Ambulância & ACI \\
\hline Trabalho em Altura & TA \\
\hline Controle de Qualidade & CQ \\
\hline CRECHE & CRE \\
\hline
\end{tabular}

Por fim, foi constatado que, com o quadro de funcionários atual é impossível equilibrar a relação oferta versus demanda de exames periódicos a serem agendados anualmente. Sugere-se então que haja um aumento do quadro de médicos responsáveis pela realização destes exames. Também é fundamental que o setor de medicina do trabalho estabeleça metas e consiga mensurar seu desempenho através de indicadores, como por exemplo a taxa de exames periódicos realizados (\% de exames periódicos realizados/ demanda no mesmo período), para que assim possa estabelecer planos de ações que melhorem a eficiência dos seus processos internos, além de guiar seu planejamento estratégico com programas que façam jus às maiores necessidades do quadro de funcionários da instituição. "Estratégias analíticas de longo prazo e mais robustas permitiriam a tomada de decisão informada e a ação sobre alguns pontos críticos à prestação de um cuidado efetivo, seguro, adequado, centrado no paciente, equânime e igualmente eficiente no uso dos recursos" (12).

\section{CONCLUSÃO}

O exame periódico não pode ser considerado apenas como uma obrigação legal, e sim como um momento chave para aproximar os funcionários, oferecer a prevenção e a promoção da saúde do trabalhador, sensibilizar quanto a importância do exame e estimular o autocuidado. Atualmente, na instituição analisada, os funcionários consideram este exame como uma obrigação e não conseguem entender a sua importância. Para mudar esta realidade, é necessário melhorar não apenas a gestão do agendamento, mas uma série de processos relacionados ao SESMT. Por exemplo, os médicos responsáveis pela realização dos exames devem conhecer as atividades laborais da empresa, seu perfil epidemiológico, os riscos ocupacionais e a sua gestão. Além de estarem preparados para realizar uma boa anamnese e exame físico, e fornecerem orientações de prevenção e promoção da saúde (7).

Para se ter um serviço de medicina do trabalho eficiente, também é fundamental que haja confiabilidade dos funcionários com o serviço prestado. Para isso, o sigilo médico é algo que deve ser sempre valorizado. Dessa forma, o modelo propõe que o agendamento seja baseado em uma relação direta 
entre o WorkStation e os funcionários, tendo uma menor intervenção dos CGPs. Isto melhoraria também a proximidade dos funcionários com o SESMT, outro ponto observado nas reuniões de benchmarking realizadas.

Outras propostas que ajudariam a reduzir o número de exames periódicos vencidos e melhorariam a relação oferta versus demanda, são: buscar parceria com a faculdade de medicina da própria instituição, para receber residentes de clínica geral e/ou medicina do trabalho que pudessem ajudar nos atendimentos e, a longo prazo, ter uma equipe de medicina do trabalho para cada Instituto, como acontece na multinacional visitada.

Por fim, conclui-se que, uma melhor gestão do agendamento permite uma maior agilidade na realização dos exames e consequentemente um aumento da satisfação dos clientes. Uma boa forma de lidar com esses fatores é utilizando o modelo proposto, baseado em três pilares: lean, ética e estabilidade de processo. Ter um software que facilite esta gestão, enviando lembretes de confirmação de consultas via e-mail ou SMS, também ajudaria. Lembrando que, para garantir a qualidade dos serviços, é necessário conhecer e gerenciar os processos envolvidos, bem como monitorá-los buscando a melhoria contínua. 


\section{REFERÊNCIAS}

1. Silva ESN, Santos TFV. Análise dos padrões técnicos de Programas de Controle Médico de Saúde Ocupacional e Atestados de Saúde Ocupacional por meio de auditoria interna. Revista Brasileira de Medicina do Trabalho. 2014; 12(2): 50-6. Disponível em: http://www.rbmt.org.br/details/48/enUS/analise-dos-padroes-tecnicos-de-programas-de-controle-medico-desaude-ocupacional-e-atestados-de-saude-ocupacional-por-meio-deauditoria-interna

2. Ribeiro FPL. Auditoria de Programa de Controle Médico e Saúde Ocupacional: proposta de protocolo específico a partir das exigências da Norma Regulamentadora $\mathrm{n}^{\circ}$ 7. Revista Brasileira Medicina do Trabalho. 2014; 12(2): 57-65. Disponível em: http://www.rbmt.org.br/about-theauthors/49/pt-BR

3. Brasil. Ministério do Trabalho e Emprego. NR4 - Norma Regulamentadora 4 - Serviços Especializados em Engenharia de Segurança e em Medicina do Trabalho. Brasília, DF, 27 de outubro de 1983 [Internet]. [Acesso em 22 abr. 2018]. Disponível em: http://trabalho.gov.br/images/Documentos/SST/NR/NR4.pdf

4. Brasil. Ministério do Trabalho e Emprego. NR7 - Norma Regulamentadora 7 - Programa de Controle Médico de Saúde Ocupacional. Brasília, DF, 29 de dezembro de 1994 [Internet]. [Acesso em: 22 abr. 2018]. Disponível em: http://trabalho.gov.br/images/Documentos/SST/NR/NR7.pdf

5. Brasil. Ministério do Trabalho e Emprego. NR9 - Norma Regulamentadora 9 - Programa de Prevenção de Riscos Ambientais. Brasília, DF, 29 de dezembro de 1994 [Internet]. [Acesso em: 22 abr. 2018]. Disponível em: http://trabalho.gov.br/images/Documentos/SST/NR/NR9.pdf

6. Silva A, Ferraz L; Rodrigues-Junior SA. Ações em saúde do trabalhador desenvolvidas na Atenção Primária no município de Chapecó, Santa Catarina. Revista Brasileira de Saúde Ocupacional, São Paulo. 2016; 41(16): 1-9. Disponível em: http://www.scielo.br/pdf/rbso/v41/2317-6369rbso-41-e16.pdf

7. Hyeda A, Costa ESM, Ferreira JCC. Gestão da qualidade dos exames médicos do programa de saúde ocupacional da empresa: uma análise preliminar. Revista Brasileira de Medicina do Trabalho. 2014; 12(2): 66-72. Disponível em: http://www.rbmt.org.br/details/50/pt-BR/gestao-da-qualidadedos-exames-medicos-do-programa-de-saude-ocupacional-da-empresa-uma-analise-preliminar

8. Braun TCA, et al. Análise do processo de atendimento aos clientes de uma empresa de medicina do trabalho do Vale do Sinos: Um Estudo de Caso. Revista Acadêmica São Marcos, Alvorada; 2016 p.77-105. Disponível em: http://www.saomarcos.br/ojs/index.php/rasm/article/view/137/117 
9. Castro MDG, Valle LGB, Gordono FS. Metodologia lean aplicada no gerenciamento de projetos. Integrada Revista Científica FACOL/ISEOL, Lençóis Paulista. 2014; 1(1): 69-82. Disponível em:

http://facol.br/revista/pdf/5b731e2a8411a v1 n1 2014-art05 castro.pdf

10. Villas-Bôas ME. O direito-dever de sigilo na proteção ao paciente. Revista Bioética. 2015; 23(3): 513-23. Disponível em: http://www.scielo.br/pdf/bioet/v23n3/1983-8034-bioet-23-3-0513.pdf

11. Carvalho E, Bollela VR. Agendamento Eletrônico do Paciente (AEP) como ferramenta de gestão dos ambulatórios de um serviço de referência terciária em saúde. Revista Eletrônica Gestão \& Saúde. 2015; 6(2): 1446-62.

Disponível em: http://periodicos.unb.br/index.php/rgs/article/view/2959

12. Albuquerque $C$, Martins M. Indicadores de desempenho no Sistema Único de Saúde: uma avaliação dos avanços e lacunas. Saúde debate [Internet]. 2017 Mar [Acesso em: 22 abr. 2018]; 41(spe): 118-137. Disponível em: http://www.scielo.br/pdf/sdeb/v41nspe/0103-1104-sdeb-41-nspe-0118.pdf

Recebido: 25 de fevereiro de 2019. Aceito: 18 de março de 2019

Correspondência: Eulália Oliveira Bekkers. Av. Dr. Enéas Carvalho de Aguiar, 255 - Cerqueira César, São Paulo - SP, 05403-000. E-mail:

eulaliabekkers@gmail.com

Conflito de Interesses: os autores declararam não haver conflito de interesses.

(C) This is an Open Access article distributed under the terms of the Creative Commons Attribution License, which permits unrestricted use, distribution, and reproduction in any medium, provided the original work is properly cited 